\title{
Effects of Two Problem Solving Methods on Senior Secondary School Students' Performance in Simultaneous Equations in Ekiti State
}

\author{
E. B. Kolawole \\ Prof, Institute of Education \& Department of Science Education. \\ Faculty of Education, Ekiti State University \\ O. F. Ojo \\ Institute of Education \& Department of Science Education. \\ Faculty of Education, Ekiti State University
}

\begin{abstract}
The study investigated the Effects of two Problem Solving Methods on Senior Secondary School Students' performance in Simultaneous Equations in Ekiti State. The study employed quasi experimental pre-test post-test, control group design. The sample consisted of 302 senior secondary school II students. Multistage sampling procedures were used to select the sample. The instrument used for the study was a test format tagged "Mathematics Performance test (MPT)".The face and content validity of the instrument was ascertained while test retest method was used to ensure the reliability which yielded reliability coefficient of 0.71 . Data collected were analysed descriptively using mean, standard deviation for the research question, Analysis of Variance (ANOVA) and Analysis of Covariance (ANCOVA) were used for hypotheses one and two respectively both at 0.05 level of significance. The findings revealed that, the use of KPS and PPS enhanced better performance of senior secondary school students in simultaneous equations than the CM. KPS was most effective for enhancing better students' performance in simultaneous equations, followed by PPS method and lastly conventional method. It was therefore recommended that the use of KPS and PPS methods should be encouraged in Mathematics to enhance better performance of students in simultaneous equations. Also, Mathematics teachers should be given adequate orientation through workshops and seminars to update their knowledge in the use of KPS and PPS methods in teaching.
\end{abstract}

Keywords: Problem Solving Methods, Kolawole's Problem Solving (KPS) method, Polya's Problem Solving (PPS) method, Conventional method, performance, Simultaneous Equations

\section{INTRODUCTION}

Mathematics is one of the basic subjects every child must attempt and pass in his/her life to acquire education. This important position occupied by the subject in the school curricula is borne out of the role of Mathematics in the nation's aspiration for scientific and technological developments. Kolawole (2004) described Mathematics as the backbone of a nation which enables us to make scientific predictions that are to be drawn on the basis of logic. Unfortunately, students' knowledge and performance in this important subject over the years have not been encouraging especially at the secondary level of education with particular reference to solving of simultaneous equations, an aspect in algebraic expressions.

Algebra is one of the components of Mathematics that moves students beyond an emphasis on arithmetic operations that focus on the use of symbols to represent numbers and express mathematical relationships. In algebraic expression, an equation is a mathematical statement 
that shows equality between two expressions (Adu, 2000). But equations which arise out of practical problems in many ways usually consist of more or less complicated expression on both sides of the equation. Thus, there are different forms of equations, one of which is linear equation.

An equation is said to be linear when the power of the variable is one (Ilori, Jahun \& Omeni, 2000). Meanwhile, Adu (2000) described a linear equation as a mathematical statement that contains only terms in one variable and constant where the highest power of the variable is one. David-Osuagwu, Anemelus and Onyeozili (2010) described linear equation as an equation of the form $\boldsymbol{a} \boldsymbol{x}+\boldsymbol{b}=\mathbf{0}$ where $\mathbf{a}$ and $\mathbf{b}$ are constants and $\mathbf{x}$ is the unknown variable with power of one. Using different operations, linear equations are solved by finding values of the different variables unknown that satisfies the equation(s) (Adu, 2000). On the other hand, Kolawole described general form of linear equation as any expression expressed in form of $\mathrm{a}_{1} \mathrm{x}_{1}+\mathrm{a}_{2} \mathrm{x}_{2}+\ldots \ldots+\mathrm{a}_{\mathrm{n}} \mathrm{x}_{\mathrm{n}}=\mathrm{b}$, where $\mathrm{x}_{1}, \mathrm{x}_{2} \ldots \ldots \mathrm{x}_{\mathrm{n}}$ are unknown $\mathrm{n}$ variables whose exponent is one and $\mathrm{a}_{1}, \mathrm{a}_{2} \ldots . . \mathrm{a}_{\mathrm{n}}$ are their respective coefficients, $\mathrm{a}_{\mathrm{i}}$ and $\mathrm{b}$ are constants. Therefore, in solving any given equation, David-Osuagwu etal (2010) itemised four steps to be taken without changing the equations. These include adding same quantity to both sides of the equation; subtract same quantity from both sides of the equation; multiply both sides by the same quantity and dividing both sides with same quantity not zero.

Linear equations, like linear expression may have more than one unknown variables. For instance, $3 \mathrm{x}-4 \mathrm{y}=5$ and $2 \mathrm{y}-4 \mathrm{y}=5$ are linear equations in two unknown variables. Hence, Adu (2000) described that, when two or more equations in two or more unknown variables are to be solved at the same time and the values of the unknowns satisfy the equations, such equations are termed simultaneous equations. Therefore, a simultaneous equation can be summarised as a set or system of equations containing multiple variables which has a solution that simultaneously satisfies all of the equations. For example, in the set of simultaneous linear equations: $2 x+3 y=7$ and $5 x+2 y=12$, the letters $x$ and $y$ are called variables or unknowns. Simultaneous equations are so called because the solution solves all the equations at the same time, or simultaneously. David-Osuagwu et al (2010), explained that, simultaneous linear equations are equations of the form $a x+b y=c$ and $d x+$ ey $=f$, where $a, b, c, d$, e and $f$ are constants and $\mathrm{x}$ and $\mathrm{y}$ are the unknown variables.

Considering the complexity of simultaneous linear equations, it appears that while students may find it so easy to solve linear equations in one unknown variable, it is more challenging to them when faced with simultaneous equations. Consequently, while students are still struggling with this compounding problem in simultaneous equations, Mathematics teachers are left with the problem of which of the methods of solving simultaneous equations to be chosen and when necessary to use them.

To the students, it is the problem of how to understand the complexity of simultaneous equations while teachers combat the problem of what method will take care of students' fear of understanding simultaneous equations (Onyeozili, 2010). To support the findings of Onyeozili, the researcher moved round some public secondary schools in Ekiti State and sampled the opinion of students as regards their area of difficulties in Mathematics, in which simultaneous equations is one of the topics mentioned. Thus, the researchers observed that, the reason for the students' percieved diffculties in simultaneous equations cannot be unconnected with ineffectiveness of the conventional method of instruction generally adopted by Mathematics teachers in the nation, which might not be potent enough to help students in solving their learning problems in Mathematics. According to Kolawole and Ojo (2016), Aiyelabegan, (2003) and several other researchers, the use of conventional method to teach students in school 
diminishes their interest and ability to grasp relevant underlying concepts because this approach to teach Mathematics encourages students to be passive, more direction followers and without personal initiative. In addition, Taplin (2000) and Adunola (2011) argued that the teaching method adopted by teachers greatly influences the ease at which learning instructions are comprehended and internalized.

A study carried out by Akor (2005) to determine the effects of Polya's problem-solving method in the teaching of geometry on secondary school students' achievement and interest, revealed that, Polya's problem-solving method enhances students' achievement in geometry more than the conventional method. In a study carried out by Kolawole, Oladosu and Ajetunmobi, (2013) it was revealed that, KPS method on application in some selected schools yielded better results than the conventional method in vogue in Nigerian schools. Therefore, this study intends to find out the effects of two problem solving methods on senior secondary school students' performance in simultaneous equations in Ekiti State.

\section{Statement of the Problem}

The state of teaching-learning process in Nigerian secondary schools calls for review, as most of the teachers in the public secondary schools still believe in the conventional method of teaching in the classroom. The conventional method of teaching seems to have limited the extent to which teachers can move with the trend of changes in the global world.

It seems that, teaching and learning of simultaneous linear equations has long been seen in Mathematics as a source of difficulties in solving equations in algebraic expression. Perhaps, students' challenges and difficulties in solving simultaneous equations lie on their misunderstanding of most of the methods used in solving the equations. Previous researches in this field have observed that, many difficulties in solving simultaneous equations may be related to teachers' approach to methods of solving simultaneous equation. It is against this backdrop that this paper answered the research question that:

1. What are the effects of Kolawole's Problem Solving (KPS), Polya's Problem Solving (PPS) and Conventional methods (CM) on students' performance in solving simultaneous equations?

\section{Research Hypotheses}

The following research hypotheses were generated for the study:

1. There is no significant difference in the pre-test mean scores of the experimental and control groups.

2. There is no significant difference in the effect of KPS, PPS and CM methods on students' performance when taught simultaneous equations.

\section{METHODOLOGY}

The study adopted quasi-experimental (intact class) pre-test, post-test, control group design. Kolawole's Problem Solving (KPS) and Polya's Problem Solving (PPS) were used to teach students in the experimental groups while the control group was taught with normal conventional method without a targeted teaching method. The population of this study consisted of all public Senior Secondary School two (SSSII) students in all the public Senior Secondary Schools in Ekiti State while the sample for this study was 302 Senior Secondary School II Mathematics students whose selection was based on multistage sampling procedure. The instrument used for the study was a test format tagged "Mathematics Performance test (MPT)". To ascertain the face and content validity of the instrument, it was given to experts in Tests, Measurement and Evaluation for scrutiny. Test retest method was used to ensure the reliability which yielded reliability coefficient of 0.71 . through the use of Pearson's Product 
Moment Correlation Coefficient Analysis. Data collected were analysed using descriptive and inferential statistics.

\section{RESULTS}

Question: What are the effects of students' performance in solving simultaneous equations in Kolawole's Problem Solving (KPS),Polya's Problem Solving (PPS) and Conventional methods $(\mathrm{CM}) ?$

Table 1: Effect of students' performance in solving simultaneous equations using KPS, PPS and conventional methods

\begin{tabular}{|c|c|c|c|c|c|c|c|}
\hline \multirow[t]{2}{*}{ Methods } & \multirow[t]{2}{*}{$\mathbf{N}$} & \multicolumn{2}{|c|}{ Pretest } & \multicolumn{2}{|c|}{ Posttest } & \multirow{2}{*}{$\begin{array}{c}\text { Mean } \\
\text { Difference }\end{array}$} & \multirow{2}{*}{$\begin{array}{c}\text { Relative } \\
\text { Performance }\end{array}$} \\
\hline & & Mean & SD & Mean & SD & & \\
\hline KPS & 133 & 36.02 & 5.30 & 59.88 & 2.06 & 23.86 & $1^{\text {st }}$ Position \\
\hline PPS & 74 & 36.91 & 4.09 & 53.45 & 4.71 & 16.54 & $2^{\text {nd }}$ Position \\
\hline CM & 95 & 37.27 & 1.90 & 47.97 & 2.04 & 12.70 & $3^{\text {rd }}$ Position \\
\hline Grand Total & 302 & 36.63 & 4.22 & 54.56 & 6.74 & & \\
\hline
\end{tabular}

Table 1 shows that, students exposed to KPS, PPS and conventional methods had mean scores of $36.02,36.91$ and 37.27 respectively prior to treatment. With the grand mean total of 36.63 , it appears that the groups are homogenous. On exposure to treatment, with the grand mean total of 54.56, students taught with KPS method had the highest mean score of 59.88, closely followed by those exposed to PPS method (mean $=53.45$ ) while the students in the conventional group had the least mean score of 47.97. This implies that, the use of KPS method appears to be most effective, followed by PPS method and CM respectively in enhancing the performance of students in solving simultaneous equations. Students' performance in simultaneous equation before and after treatment is presented in Figure 2.

Figure 1: effects of students' performance in solving simultaneous equations using KPS, PPS and conventional (CM) methods

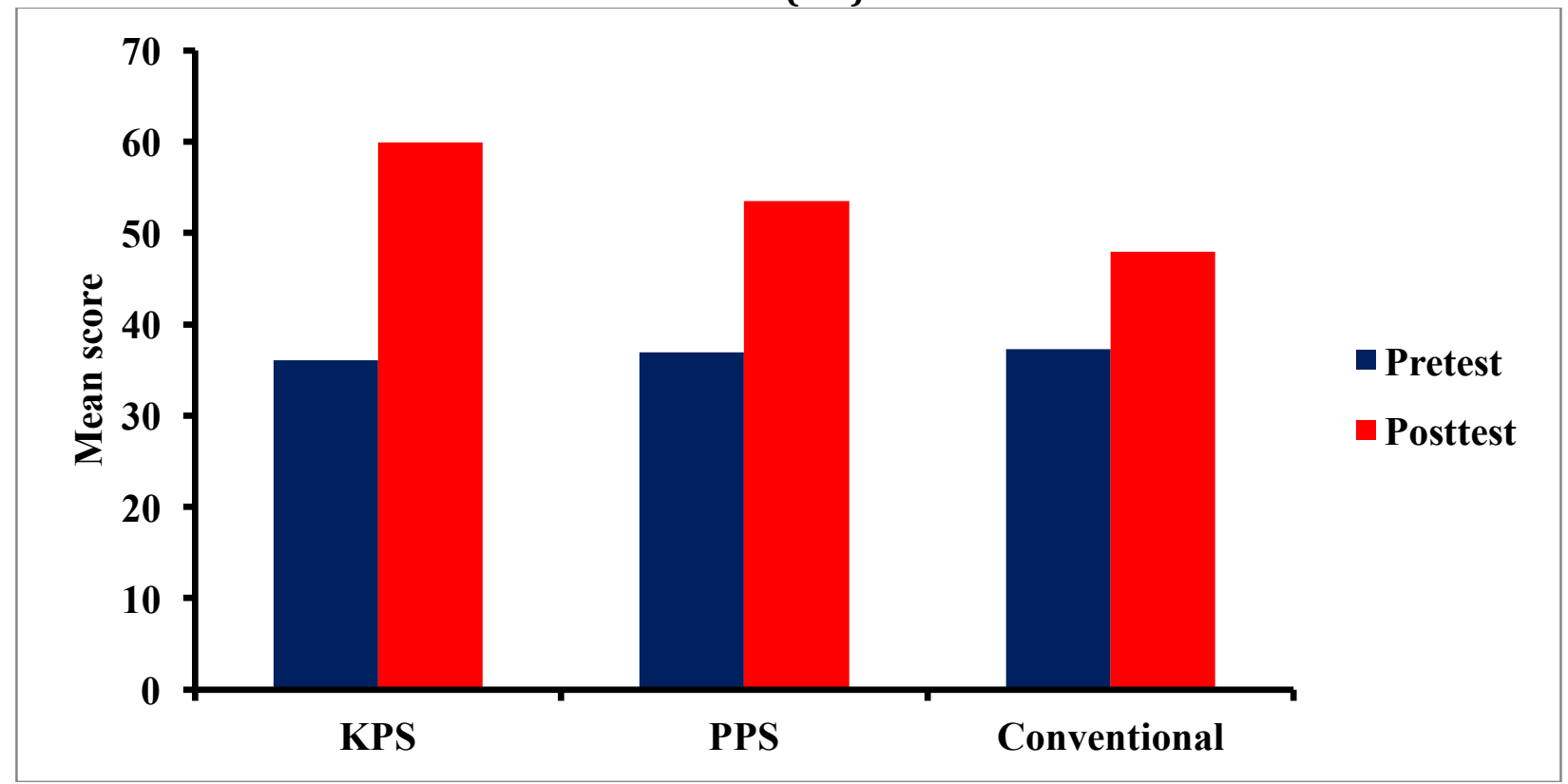

\section{Testing of Hypotheses}

The research hypotheses generated in the study were tested using Analysis of Variance (ANOVA), Analysis of Covariance (ANCOVA) at 0.05 level of significance and Multiple Classification Analysis (MCA). 
Hypothesis 1: There is no significant difference in the pre-test mean scores of the experimental and control groups.

Table 2: ANOVA summary of students' performance exposed to KPS, PPS and CM methods in simultaneous equations before treatment

\begin{tabular}{|l|c|c|c|c|c|}
\hline Source & SS & Df & MS & F & P \\
\hline Between Groups & 95.390 & 2 & 47.695 & \multirow{2}{*}{2.720} & \multirow{2}{*}{0.068} \\
\cline { 1 - 4 } Within Groups & 5269.676 & 300 & 17.536 & & \\
\hline Total & 5356.066 & 302 & & & \\
\hline
\end{tabular}

$\mathrm{p}>0.05$

The result in Table 2 reveals that $\left(\mathrm{F}_{2,300}=2.720, \mathrm{p}=0.068>0.05\right)$. The hypothesis is not rejected. This implies that, there is no significant difference in the pre-test mean scores of students exposed to KPS, PPS and CM methods. This shows that the three groups were homogeneous at the commencement of the experiment.

Hypothesis 2: There is no significant difference in the effect of KPS, PPS and CM methods on students' performance when taught simultaneous equations.

Table 3: ANCOVA showing difference in experimental and control groups

\begin{tabular}{|l|c|c|c|c|c|}
\hline Source & SS & Df & MS & F & P \\
\hline Corrected Model & 8767.703 & 3 & 2922.568 & 177.203 & .000 \\
\hline Covariate (Pretest) & 784.425 & 1 & 784.425 & 47.562 & .000 \\
\hline Group & 8509.517 & 2 & 4254.758 & 257.977 & .000 \\
\hline Error & 4914.840 & 298 & 16.493 & & \\
\hline Total & 912552.000 & 302 & & & \\
\hline Corrected Total & 13682.543 & 301 & & & \\
\hline
\end{tabular}

${ }^{*} \mathrm{p}<0.05$

The result in Table 3 reveals that $\left(\mathrm{F}_{2,298}=257.977, \mathrm{p}=0.000<0.05\right)$. The hypothesis is rejected. This implies that, there is significant effect in the mean scores of students between KPS, PPS and CM methods when taught simultaneous equations.

In order to determine the effect of treatment on the performance of students in simultaneous equations, Multiple Classification Analysis (MCA) was carried out. The result is presented in Table 4.

\section{Table 4: Multiple Classification Analysis of mean scores of students in PPS and conventional groups}

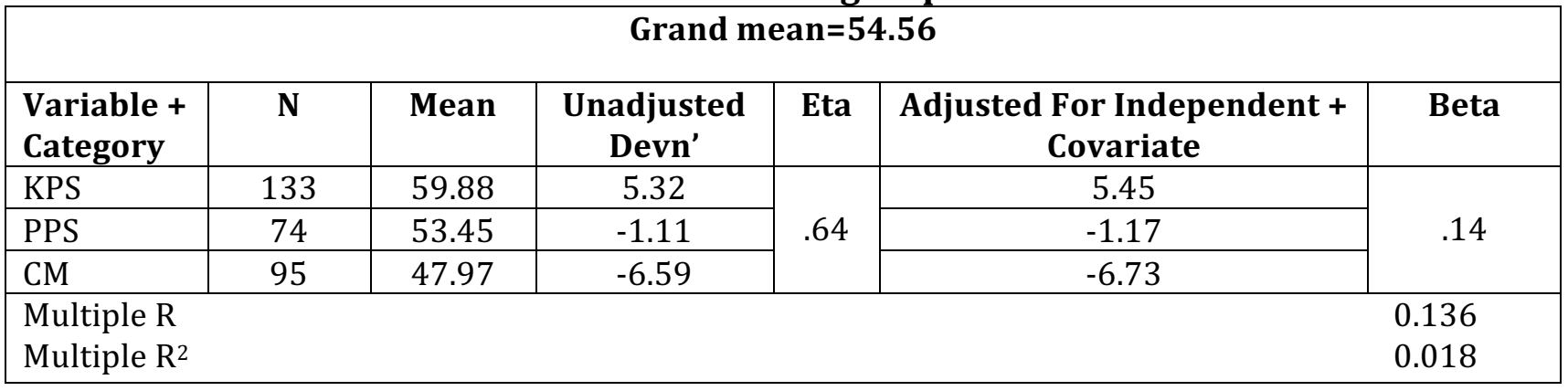

Table 4 reveals that, students in the KPS group had highest adjusted mean score of 60.01 $(54.56+5.45)$, closely followed by those in the PPS group; $53.39(54.56+(-1.17)$ while students 
in the conventional with an adjusted mean score of $47.83(54.56+(-6.73)$. This means that only KPS scored 5.45 above the grand mean of 54.56. Though, PPS narrowly scored below the grand mean with 1.17, while CM is 6.59 below the grand mean. This implies that, the use of KPS and PPS methods enhanced students' performances in simultaneous equations. About $64 \%$ $\left(\mathrm{Eta}^{2}=0.64\right)$ of the observed variance in students' performance in simultaneous is largely due to the effectiveness of the treatment. Thus, KPS is the most effective method that enhances students' performance in solving simultaneous equations, followed by PPS and lastly CM.

\section{DISCUSSION}

It was revealed in the findings of this study that, the performance of students in both experimental and control groups in pre-test were low and do not differ statistically. This shows the homogeneity of the three groups involved in the study before the experiment. This may probably be due to the possible ineffectiveness of the conventional method of instruction generally adopted by Mathematics teachers in the nation, which might not be potent enough to help students in solving their learning problems in Mathematics. The study conforms to assertion of Aiyelabegan, (2003) and several other researchers, who were of the opinion that, the use of conventional method to teach students in school diminishes their interest and ability to grasp relevant underlying concepts because this approach to teach Mathematics encourages students to be passive, more direction followers and without personal initiative.

Another major findings of this study shows that, there was a better improvement in the performance of students resulting from their exposure to Kolawole's problem solving (KPS) and Polya problem solving (PPS) methods. This implies that, the introduction of KPS and PPS to the experimental groups made them to perform better than the control group that was not exposed to treatment. This is in agreement with the assertion of Taplin (2000) and Adunola (2011) respectively, that the teaching method adopted by teachers greatly influences the ease at which learning instructions are comprehended and internalized. The finding also conforms to Akor (2005) who carried out a study to determine the effects of Polya's problem-solving strategy in the teaching of geometry on secondary school students' achievement and interest. The results of the study showed that, Polya's problem-solving strategy enhances students' achievement in geometry more than the conventional method. Also, the findings of Kolawole, Oladosu and Ajetunmobi, (2013) shows that, KPS method on application in some selected schools yielded better results than the conventional method in vogue in Nigerian schools.

\section{CONCLUSION AND RECOMMENDATIONS}

Based on the findings of this study, the three groups (KPS, PPS and CM) were homogenous at the commencement of the experiment. The use of KPS and PPS enhanced better performance of senior secondary school students in simultaneous equations than the CM. KPS is most effective for enhancing better students' performance in simultaneous equations, followed by PPS method and lastly conventional method. It is therefore recommended that the use of KPS and PPS methods should be encouraged in Mathematics to enhance better learning performance of students in simultaneous equations. Also, Mathematics teachers should be given adequate orientation through workshops and seminars to update their knowledge in the use of KPS and PPS methods in teaching.

\section{References}

Adu, D.B. (2000). Comprehensive Mathematics for senior secondary schools. Surulere, Lagos: A. Johnson Publishers LTD.

Adunola, 0. (2011). The impact of teachers' teaching methods on the academic performance of primary school pupils in Ijebu-Ode Local Area of Ogun State. Ego Booster Books: Ogun State, Nigeria. 
Ahmad, A.W. \& Shahrill, M. (2014). Improving post-secondary students' algebraic skills in the learning of complex numbers. International Journal of science and Research, 3(8), 273-279

Aiyelabegan, A.T. (2003). Effect of Physics practical on students' academic performance in senior school certificate Physics examination in Kwara State. Lafiagi Journal of Science Education, 5(1\&2), 84-89.

Akor, E.A.P. (2005). Effects of Polya's problem solving strategy in teaching geometry on secondary school students' achievement and interest. Unpublished M.Ed project report, University of Nigeria Nsukka.

David-Osuagwu, M.N.; Anemelu, C. \& Onyeozili, I. (2010). New school Mathematics for senior secondary schools. Onitsha: Africans First Publishers plc.

Ilori, S.A.; Jahun, I.U. \& Omeni. B.A (2000). Exam focus Mathematics for WASSCE and SSCE. Ibadan university press, PLC.

Kolawole, E.B. (2004). The effect of home background and peer group on secondary school students' academic performance in Mathematics in Ekiti State. Journal of Contemporary Issues in Education. 2(1), 197.

Kolawole, E.B.; Oladosu, C.T \& Ajetunmobi, O. (2013). Comparability of effectiveness of problem solving methods on learners' performance in Mathematics. Unique Journal of Education Research. 1(2), 12-18.

Kolawole, E.B. \& Ojo. O. (2016). Statistical analysis of the effects of Kolawole's Problem Solving (KPS) and conventional teaching methods on the academic performance and retention of senior secondary school students in Mathematics in Ekiti State, Nigeria. Research Journal in Education, 2(6), 100-109.

Onyeozili, I. (2010). New school Mathematics for senior secondary schools. Onitsha: Africans First Publishers plc.

Taplin, M. (2000). Spatial patterning: A pilot study of pattern formation and generalisation. In L. Meira \& D. Carraher (Eds.), Proceedings of the 19th Conference of the International Group for the Psychology of Mathematics Education, 3, 42-49. Brazil Recife. 